\title{
Determinants of Periprocedural Myocardial Infarction in Current Elective Percutaneous Coronary Interventions
}

\author{
Yusuke Mizuno, ${ }^{1}$ MD, Kenichi Sakakura, ${ }^{1}$ MD, Kei Yamamoto, ${ }^{1}$ MD, Yousuke Taniguchi, ${ }^{1}$ MD, \\ Takunori Tsukui, ${ }^{1}$ MD, Masaru Seguchi, ${ }^{1}$ MD, Hiroshi Wada, ${ }^{1}$ MD, Shin-ichi Momomura, ${ }^{1}$ MD and \\ Hideo Fujita, ${ }^{1}$ MD
}

\begin{abstract}
Summary
Periprocedural myocardial infarction (PMI) is closely associated with long-term cardiovascular events. The factors associated with PMI are not fully understood. The purpose of this study was to investigate the determinants of PMI in contemporary elective percutaneous coronary intervention (PCI). Overall, 731 elective PCI was divided into the PMI $(n=27)$ and non-PMI $(n=704)$ groups. Univariate and multivariate logistic regression analysis was used to find factors associated with PMI. In the univariate analysis, PMI was associated with complex lesion characteristics, such as the lesion length, lesion angle, calcification, and Medina classification. In the multivariate logistic regression analysis, the lesion length (per 10-mm increase: odds ratio (OR), 1.477; 95\% confidence interval $(\mathrm{CI}), 1.161-1.879 ; P=0.002$ ), lesion angle $\geq 45^{\circ}$ (versus lesion angle $<45^{\circ}: \mathrm{OR}, 4.244$; 95\% CI, $1.187-15.171 ; P=0.026)$, and Medina classification $(0,1,1) /(1,1,1)$ (versus other lesions: OR, 14.843; 95\% CI, 6.235 - 35.334; $P<0.001$ ) were significantly associated with PMI. Of the 24 lesions with lesion angle $\geq 45^{\circ}$ in the PMI group, 14 had final TIMI flow grade $\leq 2$ in side branches and 9 had transient slow flow in main branches/transient ST elevation during PCI. Of the 87 lesions with Medina classification $(1,1,1) /(0,1,1), 19$ had final TIMI grade $\leq 2$ in side branches. In conclusion, the lesion length, lesion angle $\geq 45^{\circ}$, and Medina classification $(0,1,1) /(1,1,1)$ were significantly associated with PMI in contemporary elective PCI. Preventing flow limitation in both side branches and main vessels in elective PCI for the diffuse long, angulated, or true bifurcation lesions is important.
\end{abstract}

Key words: Bifurcation, Complications, Medina classification

(Int Heart J 2020; 61: 1121-1128)

$\mathrm{P}$ ercutaneous coronary intervention (PCI) plays an important role for the treatment of ischemic heart diseases. ${ }^{1,2)}$ The development of devices such as balloons, microcatheters, and stents has improved the quality of PCI and decreased the incidence of complications, especially in elective PCI. ${ }^{1,-5)}$ However, complications such as periprocedural myocardial infarction (PMI) still exist. ${ }^{6.7)}$ Although the incidence of PMI widely varied among $2 \%-30 \%$, which depended on the definitions of PMI, PMI was associated with future cardiovascular events, including cardiac death. ${ }^{7-11)}$ Earlier studies reported the relationship between PMI and clinical factors such as lesion/stent length, bifurcation lesions, SYNTAX score, and left main disease. ${ }^{7,9,12,13)}$ However, the factors associated with PMI in contemporary elective PCI were not fully understood. Therefore, the aim of this study was to investigate the determinants of PMI in contemporary elective PCI.

\begin{abstract}
Methods
Study lesions: This was a retrospective, single-center study. We reviewed all PCI cases in the Saitama Medical Center, Jichi Medical University, from January 2018 to March 2019. The inclusion criterion was elective PCI cases performed during the study period. Elective PCI cases included the culprit lesions of acute myocardial infarction as long as the revascularization was performed as elective PCI. The exclusion criteria were (1) cases that did not have either CK or CK-MB values at the next day of PCI, (2) cases in which $\geq 2$ vessel were treated simultaneously, and (3) saphenous vein graft lesions. In patients whose baseline CK levels were normal, PMI was defined as an elevation of CK levels of $\geq 2$ times of the upper limit of normal (ULN) with an elevation of CK-MB levels above the ULN at the next day of PCI. ${ }^{6,14-16)}$ If baseline CK levels were already elevated, PMI was defined as further increase of CK levels at the next day of PCI than $\mathrm{CK}$ level at baseline. ${ }^{16)}$ We divided the study cases into a PMI and non-PMI groups according to the incidence of PMI.
\end{abstract}

From the ${ }^{1}$ Division of Cardiovascular Medicine, Saitama Medical Center, Jichi Medical University, Saitama, Japan.

Address for correspondence: Kenichi Sakakura, MD, Division of Cardiovascular Medicine, Saitama Medical Center, Jichi Medical University, 1-847, Amanuma, Omiya-ku, Saitama 330-8503, Japan. E-mail: ksakakura@jichi.ac.jp

Received for publication March 24, 2020. Revised and accepted July 9, 2020.

Released in advance online on J-STAGE November 13, 2020.

doi: $10.1536 /$ ihj.20-215

All rights reserved by the International Heart Journal Association. 
Bifurcation lesions were divided into seven categories according to the Medina classification system. ${ }^{17)}$ In this system, we recorded any narrowing of $\geq 50 \%$ in angiography in each of the three arterial segments of the bifurcation in the following order: proximal main vessel, distal main branch, and side branch: 1 indicates the presence of a significant stenosis and 0 indicates the absence of stenosis. ${ }^{17)}$ This study was approved by the Institutional Review Board of Saitama Medical Center, Jichi Medical University, and written informed consent was waived because of the retrospective study design.

PCI procedures: PCI procedures were performed on a biplane fluoroscopy system. The choice of PCI devices, such as guidewire, balloon, rotational atherectomy, and stent, was left at the discretion of interventional cardiologists at our cardiology center. IVUS was routinely used for almost all lesions. In bifurcation lesions, we usually insert a conventional guidewire to a side branch before stenting to the main vessel and occasionally perform jailed balloon technique/jailed corsair technique. We conducted a single stent technique and seldom selected twostent technique, especially in elective PCI. Rotational atherectomy was performed to moderate or severely calcified lesions, diffuse lesions expected to be difficult to stent, and ostial lesions. ${ }^{18)}$ Our university hospital had many operators, including residents with different background. However, each PCI was strictly supervised by staff operators. Staff operators did not hesitate to take over procedures, when residents felt any difficulties in procedures. Activated coagulation time was maintained over $250 \mathrm{sec}-$ onds during procedures.

Definition: The overweight was defined as BMI $\geq 25 \mathrm{~kg} /$ $\mathrm{m}^{2} .{ }^{19)}$ Hypertension was defined as medical treatment for hypertension and/or a history of hypertension before admission. ${ }^{20)}$ Dyslipidemia was defined as a total cholesterol level $\geq 220 \mathrm{mg} / \mathrm{dL}$ or low-density lipoprotein cholesterol level $\geq 140 \mathrm{mg} / \mathrm{dL}$ or medical treatment for dyslipidemia or a history of dyslipidemia. ${ }^{21)}$ Diabetes mellitus was defined as a hemoglobin A1c level $\geq 6.5 \%$ (as NGSP value) or medical treatment for diabetes mellitus or a history of diabetes mellitus. ${ }^{21)}$ Chronic renal failure was defined as a creatinine level $\geq 2.0 \mathrm{mg} / \mathrm{dL}{ }^{18)}$ We also calculated the estimated glomerular filtration rate (eGFR) from the serum creatinine level, age, weight, and gender using the following formula: $\mathrm{eGFR}=194 \times \mathrm{Cr}-1.094 \times$ age -0.287 $($ male $)$ and $\mathrm{eGFR}=194 \times \mathrm{Cr}-1.094 \times$ age $-0.287 \times$ 0.739 (female). ${ }^{20)}$

Angiographic analysis: Quantitative coronary angiography parameters were measured using a cardiovascular angiography analysis system (QAngio XA 7.3, MEDIS Imaging Systems, Leiden, Netherlands). The lesion length and reference diameter were measured. The definition of types $\mathrm{A}, \mathrm{B} 1, \mathrm{~B} 2$, and $\mathrm{C}$ lesions has been previously described. ${ }^{22)}$ Calcification was identified as readily apparent radiopacities within the vascular wall at the site of the stenosis and was classified as none/mild, moderate (radiopacities noted only during the cardiac cycle before contrast injection), and severe (radiopacities noted without cardiac motion before contrast injection generally compromising both sides of the arterial lumen). ${ }^{23)}$

Statistical analysis: Data are presented as a percentage for categorical variables and the mean \pm standard deviation for continuous variables. The Wilk-Shapiro test was performed to determine if the continuous variables were normally distributed. Normally distributed continuous variables were compared between the two groups using Student's $t$-test. Otherwise, continuous variables were compared using Mann-Whitney $U$ test. Categorical variables were compared using a Chi-square test. Univariate and multivariate logistic regression analyses were performed to investigate associations between the clinical variables and PMI. In this model, PMI was used as the dependent variable. In the multivariate logistic regression model, the selection of independent variable was derived from the results of univariate logistic regression analysis $(P<0.05$ in univariate analysis $)$. Then, the multivariate stepwise logistic regression analysis was applied with backward elimination (likelihood ratio). The odds ratio (OR) and the 95\% confidence interval (CI) were calculated. A $P$ value of $<0.05$ was considered statistically significant. We analyzed all data using IBM SPSS statistics version 25 (Chicago, IL, USA).

\section{Results}

Overall, 759 elective PCI lesions were performed during the study period. Then, 28 PCI lesions were excluded. Our final study population was 731 patients, which was divided into the PMI $(n=27)$ and non-PMI ( $n$ $=704$ ) groups. The study flowchart is shown as the Figure. The comparison of clinical characteristics is shown in Table I. The lesion length was significantly longer in the PMI group $(30.6 \pm 4.2 \mathrm{~mm})$ than in the non-PMI group $(18.8 \pm 0.5 \mathrm{~mm} ; P<0.001)$. The reference diameter was significantly smaller in the PMI group $(2.15 \pm 0.14 \mathrm{~mm})$ than in the non-PMI group $(2.46 \pm 0.05 \mathrm{~mm} ; P<0.001)$. Rotational atherectomy was more frequently performed in the PMI group $(33.3 \%)$ than in the non-PMI group (11.9\%; $P=0.004)$.

Of the 24 lesions with lesion angle $\geq 45^{\circ}$ in the PMI group, 14 had final TIMI flow grade $\leq 2$ in side branches, 9 had transient slow flow in main branches/transient ST elevation during PCI, and 2 had transient side branch occlusion. Of the 44 lesions with Medina classification $(1,1,1), 7$ had final TIMI flow grade $\leq 2$ in side branches, in which 4 resulted in PMI. Of the 43 lesions with Medina classification $(0,1,1), 12$ had final TIMI flow grade $\leq$ 2 in side branches, in which 9 had PMI.

The univariate logistic regression model to investigate the factors associated with PMI is summarized in Table II. Complex lesion characteristics, such as lesion length, lesion angle, calcification, ACC/AHA classification, Medina classification, guiding catheter size, the use of Rotablator, and total stent/DCB length, were associated with PMI. Furthermore, LM-LAD lesions, reference diameter, the use of IABP, and final TIMI flow grade of the side branch were also associated with PMI.

We performed a multivariate stepwise logistic regression analysis by backward selection (likelihood ratio) to find the factors associated with PMI (Table III). We included LM-LAD lesions, reference diameter, lesion length, lesion angle $\geq 45^{\circ}$, calcification, Medina classifica- 


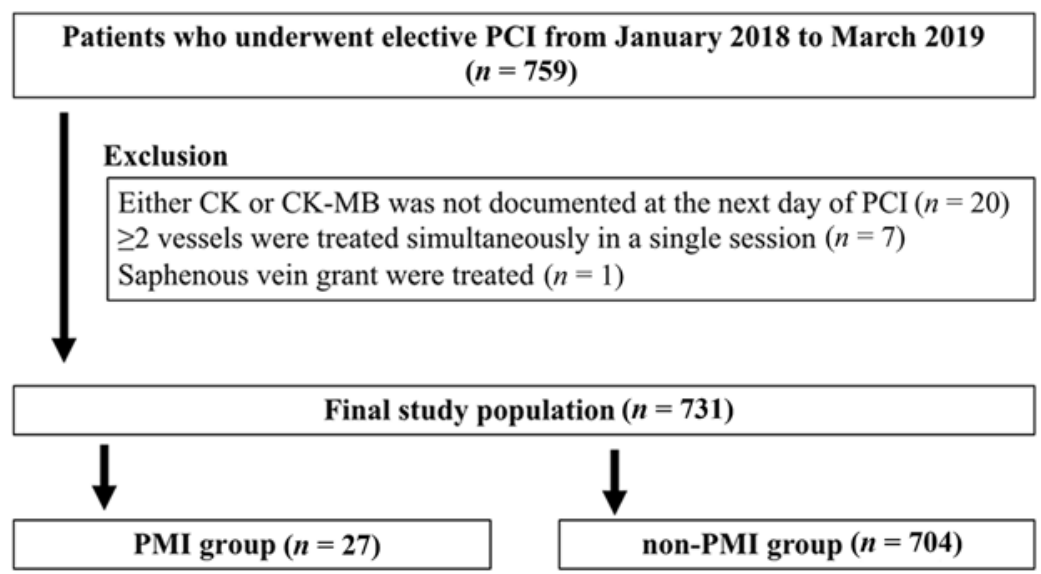

Figure. The study flowchart. PMI, periprocedural myocardial infarction.

tion, $(0,1,1) /(1,1,1)$, and the use of Rotablator. The lesion length (per 10-mm increase: OR, 1.477; 95\% CI, $1.161-$ $1.879, P=0.002$ ), lesion angle $\geq 45^{\circ}$ (versus lesion angle $<45^{\circ}$ : OR, 4.244; 95\% CI, $\left.1.187-15.171, P=0.026\right)$, and Medina classification $(0,1,1) /(1,1,1)$ (versus other lesions: OR, 14.843; 95\% CI, 6.235-35.334, $P<0.001)$ were significantly associated with PMI.

\section{Discussion}

This study aimed at finding the determinants of PMI in the contemporary elective PCI. We evaluated 731 lesions and found 27 lesions with PMI. The multivariate logistic regression analysis revealed that the lesion length, lesion angle $\geq 45^{\circ}$, and Medina classification $(0,1,1) /$ $(1,1,1)$ were significantly associated with PMI. Our results suggest the importance of sufficient preparation to prevent PMI in lesions with diffuse long, steep angle, and Medina classification $(0,1,1) /(1,1,1)$ in elective PCI.

Early studies reported the association between lesion length and PMI, ${ }^{9,13}$ which is consistent to our results. A possible explanation for the association between lesion length and PMI is the disturbance of microvascular circulation. ${ }^{24)}$ A diffuse long lesion would have larger plaque volume than the short lesion, which would increase the chance of distal embolization. ${ }^{25}$ Furthermore, the distal embolization can happen even when the coronary flow is maintained after stent deployment. ${ }^{26,27)}$ Such silent embolization may result in PMI in diffuse long lesions. ${ }^{27)}$ Another possible explanation is side branch occlusion/injury. ${ }^{24)}$ As compared to short lesions, diffuse long lesions should have more side branches, which would have a greater risk of side branch occlusion after stenting. ${ }^{28)}$

In the 24 lesions with lesion angle $\geq 45^{\circ}$ in the PMI group, persistent or transient flow limitation in side branches or main vessels was found in 21 lesions, whereas 3 lesions had transient ST elevation without apparent flow limitation. Thus, flow limitation in side branches or main vessels would be a main reason for PMI in angulated lesions. Earlier studies reported the association between lesion angle and troponin I elevation after PCI, and the mechanism would be side branch occlusion or distal embolism after stenting. ${ }^{2930)}$ Our results were consistent with these earlier studies. Performing side branch protection or recross the branch after stenting in angulated lesions might be difficult

Our result showed that the Medina classification $(1,1,1) /(0,1,1)$ was significantly associated with PMI. In contemporary elective PCI, few studies have investigated which bifurcation lesion type in the Medina classification is related to PMI. However, it is not surprising that there should be a greater risk of side branch occlusion in the Medina classification $(1,1,1) /(0,1,1)$ than in the $(1,0,1) /$ $(0,0,1)$, because diseased side branch would have a greater risk of occlusion than non-diseased side branch. Chen, et al. reported the significant association between PMI and one-year mortality in coronary bifurcation lesions. ${ }^{12}$ Therefore, for better patient outcomes, it would be important to prevent PMI following side branch occlusion in bifurcation lesions.

The clinical implications of the present study should be noted. In PCI for the diffuse long, angulated, or bifurcation lesions with Medina classification $(0,1,1) /(1,1,1)$, preventing flow limitation in both side branches and main vessels is important. However, the strategy in preventing flow limitation would be different between side branches and main vessels. For side branches, we may consider aggressive side branch protection, such as jailed balloon techniques or jailed corsair techniques. ${ }^{31,32)}$ Moreover, complex two-stent techniques may prevent inhospital complications in true bifurcation lesions and at the same time increase stent thrombosis. ${ }^{33)}$ For main vessels, the option to prevent flow limitation is limited. The distal protection device would not be indicated in most elective PCI. Vasodilators, such as nitroprusside or nicorandil, might recover coronary flow $^{34,35)}$ but would not be indicated for the prevention of slow flow. Although the use of Rotablator was not associated with PMI in the multivariate stepwise analysis, it was associated with PMI in the univariate analysis. Since slow flow is relatively common complications following Rotablator, ${ }^{36)}$ preventing slow flow following Rotablator would be important. A novel strategy to prevent microvascular embolization is warranted.

Study limitations: First, this study was a single-center 
Table I. Comparison of Patients, Lesions, and Procedural Characteristics between the PMI and Non-PMI Groups

\begin{tabular}{|c|c|c|c|c|}
\hline & All $(n=731)$ & PMI group $(n=27)$ & Non-PMI group $(n=704)$ & $P$ value \\
\hline \multicolumn{5}{|l|}{ Patient characteristics } \\
\hline Age (years) & $70.9 \pm 10.2$ & $72.1 \pm 9.4$ & $70.9 \pm 10.2$ & 0.651 \\
\hline Men, $n(\%)$ & 577 (78.9) & $19(70.4)$ & $558(79.3)$ & 0.266 \\
\hline Overweight (BMI $\left.\geq 25 \mathrm{~kg} / \mathrm{m}^{2}\right), n(\%)$ & $262(35.8)$ & $5(18.5)$ & $257(36.5)$ & 0.056 \\
\hline Hypertension, $n(\%)$ & $662(90.6)$ & $25(92.6)$ & $637(90.5)$ & 0.552 \\
\hline Diabetes mellitus, $n(\%)$ & $333(45.6)$ & $15(55.6)$ & $318(45.2)$ & 0.288 \\
\hline Hyperlipidemia, $n(\%)$ & $628(85.9)$ & $23(85.2)$ & $605(85.9)$ & 0.543 \\
\hline Current smoker, $n(\%)$ & $92(12.6)$ & $3(11.1)$ & $89(12.6)$ & 0.552 \\
\hline $\begin{array}{l}\text { Chronic renal failure (creatinine }>2 \mathrm{mg} / \mathrm{dL} \text { ), } \\
n(\%)\end{array}$ & $88(12.0)$ & $3(11.1)$ & $85(12.1)$ & 0.587 \\
\hline Estimated GFR (mL/minute/1.73 m²) & $59.2 \pm 26.6$ & $49.8 \pm 4.2$ & $59.5 \pm 1.0$ & 0.017 \\
\hline Chronic renal failure on hemodialysis, $n(\%)$ & $76(10.4)$ & $2(7.4)$ & $74(10.5)$ & 0.454 \\
\hline Statin treatment, $n(\%)$ & $577(78.9)$ & $22(81.5)$ & $555(78.8)$ & 0.741 \\
\hline Creatine kinase $(\mathrm{U} / \mathrm{L})$ at the next day of PCI & $82.0(57.0-127.0)$ & $540.0(384.0-873.0)$ & $80.0(57.0-119.8)$ & $<0.001$ \\
\hline $\begin{array}{l}\text { Creatine kinase-myocardial band (U/L) at } \\
\text { the next day of PCI }\end{array}$ & $3.0(1.0-7.0)$ & $62.0(39.0-88.0)$ & $3.0(1.00-6.00)$ & $<0.001$ \\
\hline \multicolumn{5}{|l|}{ Lesion characteristics } \\
\hline Reason for PCI & & & & 0.044 \\
\hline $\begin{array}{l}\text { PCI to the culprit of ST elevation myocar- } \\
\text { dial infarction, } n(\%)\end{array}$ & $5(0.7)$ & $1(3.7)$ & $4(0.6)$ & \\
\hline $\begin{array}{l}\text { PCI to the culprit of non-ST elevation } \\
\text { myocardial infarction, } n(\%)\end{array}$ & $92(12.6)$ & $6(22.2)$ & $86(12.2)$ & \\
\hline PCI to the non-AMI lesions, $n(\%)$ & $634(86.7)$ & $20(74.1)$ & $614(87.2)$ & \\
\hline Target lesion & & & & 0.050 \\
\hline $\begin{array}{l}\text { Left main-left anterior descending artery, } \\
n(\%)\end{array}$ & $347(47.5)$ & $18(66.7)$ & $329(46.7)$ & \\
\hline Left circumflex artery, $n(\%)$ & $147(20.1)$ & $1(3.7)$ & $146(20.7)$ & \\
\hline Right coronary artery, $n(\%)$ & $237(32.4)$ & $8(29.6)$ & $229(32.5)$ & \\
\hline PCI to in-stent restenosis, $n(\%)$ & $67(9.2)$ & $3(11.1)$ & $64(9.1)$ & 0.457 \\
\hline PCI to chronic total occlusion, $n(\%)$ & $54(7.4)$ & $3(11.1)$ & $51(7.2)$ & 0.442 \\
\hline Reference diameter (mm) & $2.45 \pm 1.27$ & $2.15 \pm 0.14$ & $2.46 \pm 0.05$ & 0.026 \\
\hline Lesion length (mm) & $19.3 \pm 13.4$ & $30.6 \pm 3.0$ & $18.8 \pm 0.5$ & $<0.001$ \\
\hline Lesion angle & & & & $<0.001$ \\
\hline Mild $\left(<45^{\circ}\right)$ & $351(48.0)$ & $3(11.1)$ & $348(49.4)$ & \\
\hline Moderate $\left(45^{\circ}-90^{\circ}\right)$ & $287(39.3)$ & $15(55.6)$ & $272(38.6)$ & \\
\hline Severe $\left(>90^{\circ}\right)$ & $93(12.7)$ & $9(33.3)$ & $84(11.9)$ & \\
\hline Calcification & & & & 0.019 \\
\hline None/mild, $n(\%)$ & $437(59.8)$ & $10(37.0)$ & $427(60.7)$ & \\
\hline Moderate, $n(\%)$ & $125(17.1)$ & $5(18.5)$ & $120(17.0)$ & \\
\hline Severe, $n(\%)$ & $169(23.1)$ & $12(44.4)$ & $157(22.3)$ & \\
\hline ACC/AHA classification & & & & 0.001 \\
\hline Type $\mathrm{A}$ and $\mathrm{B} 1$ & $211(28.9)$ & $1(3.7)$ & $210(29.8)$ & \\
\hline Type B2 & $215(29.4)$ & $6(22.2)$ & $209(29.7)$ & \\
\hline Type C & $305(41.7)$ & $20(74.1)$ & $285(40.5)$ & \\
\hline \multicolumn{5}{|l|}{ Bifurcation lesion $(n=294)$} \\
\hline Medina classification & & & & $<0.001$ \\
\hline $1,0,0$ & $26(8.8)(n=294)$ & $0(0)(n=24)$ & $26(9.6)(n=270)$ & \\
\hline $1,0,1$ & $14(4.8)(n=294)$ & $0(0)(n=24)$ & $14(5.2)(n=270)$ & \\
\hline $1,1,0$ & $87(29.6)(n=294)$ & $5(20.8)(n=24)$ & $82(30.4)(n=270)$ & \\
\hline $1,1,1$ & $44(15.0)(n=294)$ & $7(29.2)(n=24)$ & $37(13.7)(n=270)$ & \\
\hline $0,1,0$ & $61(20.7)(n=294)$ & $2(8.3)(n=24)$ & $59(21.9)(n=270)$ & \\
\hline $0,1,1$ & $43(14.6)(n=294)$ & $10(41.7)(n=24)$ & $33(12.2)(n=270)$ & \\
\hline $0,0,1$ & $19(6.5)(n=294)$ & $0(0)(n=24)$ & $19(7.0)(n=270)$ & \\
\hline \multicolumn{5}{|l|}{ Procedural characteristics } \\
\hline Successful PCI & $726(99.3)$ & $26(96.3)$ & $700(99.4)$ & 0.172 \\
\hline Guiding catheter size and system & & & & $<0.001$ \\
\hline $5 \mathrm{Fr}, n(\%)$ & $1(0.1)$ & $0(0)$ & $1(0.1)$ & \\
\hline $6 \mathrm{Fr}, n(\%)$ & $344(47.1)$ & $3(11.1)$ & $341(48.4)$ & \\
\hline $7 \mathrm{Fr}, n(\%)$ & $340(46.5)$ & $21(77.8)$ & $319(45.3)$ & \\
\hline $8 \mathrm{Fr}, n(\%)$ & $46(6.3)$ & $3(11.1)$ & $43(6.1)$ & \\
\hline Intra-aortic balloon pump support, $n(\%)$ & $7(1.0)$ & $2(7.4)$ & $5(0.7)$ & 0.025 \\
\hline Use of Rotablator, $n(\%)$ & $93(12.7)$ & $9(33.3)$ & $84(11.9)$ & 0.004 \\
\hline
\end{tabular}


Table I. Comparison of Patients, Lesions, and Procedural Characteristics between the PMI and Non-PMI Groups (continued)

\begin{tabular}{|c|c|c|c|c|}
\hline & All $(n=731)$ & PMI group $(n=27)$ & Non-PMI group $(n=704)$ & $P$ value \\
\hline Use of Diamondback $360, n(\%)$ & $18(2.5)$ & $1(3.7)$ & $17(2.4)$ & 0.496 \\
\hline $\begin{array}{l}\text { Use of scoring balloon or cutting balloon, } n \\
(\%)\end{array}$ & $204(27.9)$ & $4(14.8)$ & $200(28.4)$ & 0.121 \\
\hline Side branch protection & & & & 0.163 \\
\hline Jailed wire, $n(\%)$ & $168(23.0)$ & $10(37.0)$ & $158(22.4)$ & \\
\hline Jailed corsair, $n(\%)$ & $32(4.4)$ & $2(7.4)$ & $30(4.3)$ & \\
\hline Jailed balloon, $n(\%)$ & $2(0.3)$ & $0(0)$ & $2(0.3)$ & \\
\hline Total stent and DCB length & $30.910 \pm 17.529(n=713)$ & $48.230 \pm 27.253(n=26)$ & $30.260 \pm 16.735(n=687)$ & $<0.001$ \\
\hline Kissing balloon technique, $n(\%)$ & $9(1.2)$ & $0(0)$ & $9(1.3)$ & 0.711 \\
\hline Final TIMI grade of the main vessel & & & & 0.232 \\
\hline TIMI $3, n(\%)$ & $724(99.0)$ & $26(96.3)$ & $698(99.1)$ & \\
\hline $\mathrm{TIMI} \leq 2, n(\%)$ & $7(1.0)$ & $1(3.7)$ & $6(0.90)$ & \\
\hline $\begin{array}{l}\text { Final TIMI grade of the side branch }(n= \\
\text { 294) }\end{array}$ & & & & $<0.001$ \\
\hline TIMI $3, n(\%)$ & $263(89.5)(n=294)$ & $8(33.3)(n=24)$ & $255(94.4)(n=270)$ & \\
\hline $\mathrm{TIMI} \leq 2, n(\%)$ & $31(10.5)(n=294)$ & $16(66.7)(n=24)$ & $15(5.6)(n=270)$ & \\
\hline Final PCI procedure & & & & 0.496 \\
\hline DES, $n(\%)$ & $596(81.5)$ & $22(81.5)$ & $574(81.5)$ & \\
\hline $\mathrm{DCB}, n(\%)$ & $95(13.0)$ & $4(14.8)$ & $91(12.9)$ & \\
\hline $\mathrm{DES}+\mathrm{DCB}, n(\%)$ & $13(1.8)$ & $0(0)$ & $13(1.8)$ & \\
\hline BMS, $n(\%)$ & $8(1.1)$ & $0(0)$ & $8(1.1)$ & \\
\hline POBA, $n(\%)$ & $14(1.9)$ & $0(0)$ & $14(2.0)$ & \\
\hline Other, $n(\%)$ & $5(0.7)$ & $1(3.7)$ & $4(0.6)$ & \\
\hline
\end{tabular}

BMI indicates body mass index; GFR, glomerular filtration rate; PCI, percutaneous coronary intervention; AMI, acute myocardial infarction; DCB, drug-coated balloon; TIMI, thrombolysis in myocardial infarction; DES, drug-eluting stent; BMS, bare-metal stent; and POBA, plain old balloon angioplasty.

retrospective observational study, and there is a risk of patient and group selection bias. Our university hospital had many PCI operators during the period, which would yield an operator bias. Moreover, the frequency of Rotablator usage was greater in our catheter laboratory than in the Japanese national PCI registry, ${ }^{37}$ ) which could be an institutional bias. Second, since the strategy for bifurcation lesions depended on each PCI operator, there is also a selection bias in bifurcation procedures. Third, because the number of PMI was only 27, the direct comparison of parameters between the two groups (Table I) may not be statistically appropriate. Furthermore, the number of dependent variables in the multivariate logistic regression analysis was limited after the stepwise logistic regression model with backward elimination. Fourth, our study population was not a patient-level database, but a PCI-level database. If a patient separately received two PCIs during the study period, both PCIs were separately included. If a patient simultaneously received two PCIs, both PCIs were excluded because of the study exclusion criteria. Therefore, we could not exclude the effect of the clustered nature of one or more individual measurements from one patient. Fifth, we did not include the SYNTAX score in the present study because the SYNTAX score was a patient-level score and the SYNTAX score was not available in patients with a history of CABG $(n=27$, in the present study). Finally, we did not adopt the universal definition of PMI [cardiac troponin > 5 times the ULN and PCI-related clinical or angiographic complications], but we adopted the definition of PMI based on the rise of $\mathrm{CK} / \mathrm{CK}-\mathrm{MB}$, because the universal definition of PMI might be influenced by subjective judgment. In fact,
Tricoci, et al. reported that cardiac troponin $>5 \times \mathrm{ULN}$ was observed in $13.7 \%$ of 13,038 patients with PCI, but cardiac troponin $>5 \times$ ULN combined with clinical or angiographic complications was observed in only $2.0 \%$ of same population, ${ }^{11)}$ suggesting that PMI was judged by the clinical/angiographic complications rather than the cardiac troponin $>5 \times$ ULN. Furthermore, Ndrepepa, et al. reported that the elevation of high-sensitivity troponin $\mathrm{T}$ following PCI was observed in the majority of patients (77.6\%), which was not associated with the long-term death. ${ }^{38)}$ Appropriate selections of biomarkers and cutoff points should be important. Therefore, we judged PMI by only objective findings (CK/CK-MB) in this retrospective study.

\section{Conclusions}

In contemporary elective PCI, the lesion length, lesion angle $\geq 45^{\circ}$, and Medina classification $(0,1,1)$ or $(1,1,1)$ were significantly associated with PMI. It would be important to prevent flow limitation in both side branches and main vessels in PCI for the diffuse long, angulated, or true bifurcation lesions.

\section{Acknowledgments}

The authors acknowledge all staff in the catheter laboratory in Saitama Medical Center, Jichi Medical University, for their technical support in this study. 
Table II. Univariate Logistic Regression Model to Find the Factors Associated with Periprocedural Myocardial Infarction

\begin{tabular}{|c|c|c|c|}
\hline \multicolumn{4}{|c|}{ Dependent variable: Periprocedural myocardial infarction } \\
\hline Independent variables & Odds ratio & $95 \%$ confidence interval & $P$ value \\
\hline Age (per 1-year increase) & 1.012 & $0.974-1.053$ & 0.540 \\
\hline Male & 0.621 & $0.267-1.448$ & 0.270 \\
\hline Overweight (BMI $\geq 25 \mathrm{~kg} / \mathrm{m}^{2}$ ) & 0.395 & $0.148-1.056$ & 0.064 \\
\hline Hypertension & 1.315 & $0.305-5.673$ & 0.714 \\
\hline Diabetes mellitus & 1.517 & $0.700-3.288$ & 0.291 \\
\hline Hyperlipidemia & 0.941 & $0.319-2.779$ & 0.912 \\
\hline Current smoker & 0.864 & $0.255-2.928$ & 0.814 \\
\hline Chronic renal failure (creatinine $>2 \mathrm{mg} / \mathrm{dL}$ ) & 0.910 & $0.268-3.088$ & 0.880 \\
\hline Estimated GFR (mL/minute $\left./ 1.73 \mathrm{~m}^{2}\right)($ per10 mL/minute $/ 1.73$ increase $)$ & 0.886 & $0.772-1.018$ & 0.087 \\
\hline Chronic renal failure on hemodialysis & 0.681 & $0.158-2.934$ & 0.606 \\
\hline Statin treatment & 1.181 & $0.440-3.172$ & 0.741 \\
\hline \multicolumn{4}{|l|}{ Reason for PCI } \\
\hline PCI to the culprit of STEMI (versus the non-AMI lesions) & 2.142 & $0.837-5.482$ & 0.112 \\
\hline PCI to the culprit of NSTEMI (versus the non-AMI lesions) & 7.675 & $0.820-71.813$ & 0.074 \\
\hline PCI to in-stent restenosis & 1.250 & $0.366-4.266$ & 0.722 \\
\hline \multicolumn{4}{|l|}{ Target lesion } \\
\hline LM-LAD (versus the non-LM-LAD lesions) & 2.280 & $1.010-5.144$ & 0.047 \\
\hline PCI to chronic total occlusion & 1.600 & $0.466-5.495$ & 0.455 \\
\hline Reference diameter (per 1-mm incremental) & 0.524 & $0.281-0.977$ & 0.042 \\
\hline Lesion length (per 10-mm incremental) & 1.558 & $1.275-1.904$ & $<0.001$ \\
\hline Lesion angle $\geq 45^{\circ}\left(\right.$ versus lesion angle $\left.<45^{\circ}\right)$ & 7.820 & 2.334-26.206 & 0.001 \\
\hline \multicolumn{4}{|l|}{ Calcification } \\
\hline Moderate-severe (versus none -mild) & 2.630 & $1.187-5.828$ & 0.017 \\
\hline ACC/AHA classification type B2 and C (versus type A and B1) & 11.053 & $1.490-81.981$ & 0.019 \\
\hline \multicolumn{4}{|l|}{ Medina classification } \\
\hline$(0,1,1) /(1,1,1)($ versus the non- $0,1,1 / 1,1,1)$ & 15.397 & $6.787-34.930$ & $<0.001$ \\
\hline Guiding catheter size and system $\geq 7 \mathrm{Fr}$ (versus $6 \mathrm{Fr}$ or $5 \mathrm{Fr}$ ) & 7.558 & $2.255-25.328$ & 0.001 \\
\hline Unsuccessful PCI & 0.149 & $0.016-1.376$ & 0.093 \\
\hline DES & 0.997 & $0.370-2.681$ & 0.994 \\
\hline Use of Rotablator & 3.690 & $1.606-8.480$ & 0.002 \\
\hline Use of Diamondback 360 & 0.674 & $0.199-12.127$ & 0.645 \\
\hline Intra-aortic balloon pump support & 11.184 & $2.069-60.469$ & 0.005 \\
\hline \multicolumn{4}{|l|}{ Side branch protection } \\
\hline Jailed wire (versus no protection) & 2.169 & $0.955-4.923$ & 0.060 \\
\hline Jailed corsair/jailed balloon (versus no protection) & 2.142 & $0.469-9.773$ & 0.325 \\
\hline Any side branch protection (versus no protection) & 2.164 & $0.995-4.708$ & 0.052 \\
\hline Use of scoring balloon or cutting balloon (versus no use) & 0.437 & $0.149-1.281$ & 0.131 \\
\hline Total stent and DCB length (per 10-mm increase) & 1.421 & $1.218-1.658$ & $<0.001$ \\
\hline \multicolumn{4}{|l|}{ Final TIMI grade of the main vessel } \\
\hline TIMI $\leq 2($ versus TIMI 3$)$ & 4.474 & $0.520-38.523$ & 0.173 \\
\hline \multicolumn{4}{|l|}{ Final TIMI grade of the side branch } \\
\hline TIMI $\leq 2$ (versus TIMI 3 ) & 34.000 & $12.562-92.026$ & $<0.001$ \\
\hline
\end{tabular}

LM-LAD indicates left main-left anterior descending artery.

Table III. Multivariate Logistic Regression Model to Find the Factors Associated with Periprocedural Myocardial Infarction

\begin{tabular}{lccr}
\hline \multicolumn{2}{c}{ Dependent variable: Periprocedural myocardial infarction } \\
Independent variables & Odds ratio & $95 \%$ confidence interval & $P$ value \\
\hline Lesion length $($ per 10 -mm increase) & 1.477 & $1.161-1.879$ & 0.002 \\
Lesion angle $\geq 45^{\circ}$ (versus lesion angle $<45^{\circ}$ ) & 4.244 & $1.187-15.171$ & 0.026 \\
Medina classification $(0,1,1) /(1,1,1)($ versus other lesions) & 14.843 & $6.235-35.334$ & $<0.001$ \\
\hline
\end{tabular}

In the multivariate logistic regression model, the selection of independent variables was derived from the results of univariate logistic regression analysis $(P<0.05$ in univariate analysis): LM-LAD, reference diameter, lesion length, lesion angle $\geq 45^{\circ}$, calcification, Medina classification $(0,1,1) /(1,1,1)$, and the use of Rotablator. These variables were analyzed by backward elimination (likelihood ratio). 


\section{Disclosure}

Conflicts of interest: Dr. Sakakura has received speaking honoraria from Abbott Vascular, Boston Scientific, Medtronic Cardiovascular, Terumo, OrbusNeich, Japan Lifeline, and NIPRO; has served as a proctor for Rotablator for Boston Scientific; and has served as a consultant for Abbott Vascular and Boston Scientific. Prof. Fujita has served as a consultant for Mehergen Group Holdings, Inc.

\section{References}

1. Sabaté M, Brugaletta S, Cequier A, et al. The EXAMINATION trial (everolimus-Eluting Stents versus Bare-Metal Stents in STSegment Elevation myocardial infarction): 2-year results from a multicenter randomized controlled trial. JACC Cardiovasc Interv 2014; 7: 64-71.

2. Mohr FW, Morice MC, Kappetein AP, et al. Coronary artery bypass graft surgery versus percutaneous coronary intervention in patients with three-vessel disease and left main coronary disease: 5-year follow-up of the randomised, clinical SYNTAX trial. Lancet 2013; 381: 629-38.

3. Task Force Members, Montalescot G, Sechtem U, et al. 2013 ESC guidelines on the management of stable coronary artery disease: the Task Force on the management of stable coronary artery disease of the European Society of Cardiology. Eur Heart J 2013; 34: 2949-3003.

4. Serruys PW, Cavalcante R, Collet C, et al. Outcomes after coronary stenting or bypass surgery for men and women with unprotected left main disease: the EXCEL Trial. JACC Cardiovasc Interv 2018; 11: 1234-43.

5. Bae S, Kim Y, Gogas BD, et al. Efficacy and safety of drugeluting stents in elderly patients: A meta-analysis of randomized trials. Cardiol J 2019.

6. Jang JS, Jin HY, Seo JS, et al. Prognostic value of creatine kinase-myocardial band isoenzyme elevation following percutaneous coronary intervention: A meta-analysis. Catheter Cardiovasc Interv 2013; 81: 959-67.

7. Ben-Yehuda $\mathrm{O}$, Chen S, Redfors B, et al. Impact of large periprocedural myocardial infarction on mortality after percutaneous coronary intervention and coronary artery bypass grafting for left main disease: an analysis from the Excel trial. Eur Heart J 2019; 40: 1930-41.

8. Herrmann J. Peri-procedural myocardial injury: 2005 update. Eur Heart J 2005; 26: 2493-519.

9. Zeitouni M, Silvain J, Guedeney P, et al. Periprocedural myocardial infarction and injury in elective coronary stenting. Eur Heart J 2018; 39: 1100-9.

10. Garcia-Garcia HM, McFadden EP, von Birgelen C, et al. Impact of periprocedural myocardial biomarker elevation on mortality following elective percutaneous coronary intervention. JACC Cardiovasc Intv 2019; 12: 1954-62.

11. Tricoci P, Newby LK, Clare RM, et al. Prognostic and practical validation of current definitions of myocardial infarction associated with percutaneous coronary intervention. JACC Cardiovasc Intv 2018; 11: 856-64

12. Chen SL, Zhang JJ, Ye F, et al. Periprocedural myocardial infarction is associated with increased mortality in patients with coronary artery bifurcation lesions after implantation of a drugeluting stent. Catheter Cardiovasc Interv 2015; 85(S 1): 696705.

13. Zhang D, Li Y, Yin D, et al. Risk stratification of periprocedural myocardial infarction after percutaneous coronary intervention: analysis based on the SCAI definition. Catheter Cardiovasc Interv 2017; 89(S 1): 534-40.

14. Cavallini C, Savonitto S, Violini R, et al. Impact of the elevation of biochemical markers of myocardial damage on long-term mortality after percutaneous coronary intervention: results of the
CK-MB and PCI study. Eur Heart J 2005; 26: 1494-8.

15. Tandjung $\mathrm{K}$, van Houwelingen $\mathrm{KG}$, Jansen $\mathrm{H}$, et al. Comparison of frequency of periprocedural myocardial infarction in patients with and without diabetes mellitus to those with previously unknown but elevated glycated hemoglobin levels (from the TWENTE Trial). Am J Cardiol 2012; 110: 1561-7.

16. Vranckx P, Cutlip DE, Mehran R, et al. Myocardial infarction adjudication in contemporary all-comer stent trials: balancing sensitivity and specificity. Addendum to the historical MI definitions used in stent studies. EuroIntervention 2010; 5: 871-4.

17. Medina A, Suárez de Lezo J, Pan M. A new classification of coronary bifurcation lesions. Rev Esp Cardiol 2006; 59: 183.

18. Sakakura K, Momomura S, Fujita H. Comparison of complications with a $1.25-\mathrm{mm}$ versus a $1.5-\mathrm{mm}$ burr for severely calcified lesions that could not be crossed by an intravascular ultrasound catheter. Cardiovasc Interv Ther 2019; 34: 182-3.

19. Wolny R, Maehara A, Liu Y, et al. The obesity paradox revisited: body mass index and -long-term outcomes after PCI from a large pooled patient-level database. EuroIntervention 2020; 15: 1199-208.

20. Ohashi J, Sakakura K, Yamamoto K, et al. Determinants of improvement of mid-term ejection fraction in patients with acute myocardial infarction. Int Heart J 2019; 60: 1245-52.

21. Kasahara T, Sakakura K, Yamamoto K, et al. Clinical factors associated with in-hospital mortality in patients with acute myocardial infarction who required intra-aortic balloon pumping. Int Heart J 2020; 61: 209-14.

22. Dussaillant GR, Cumsille F, Ramírez A, et al. The classification of coronary lesion from Society for Cardiac Angiography and Intervention predicts better results of coronary angioplasty than the one from American College of Cardiology/American Heart Association Coronary Disease. Rev med Chile 2001; 129: 60510.

23. Mintz GS, Popma JJ, Pichard AD, et al. Patterns of calcification in coronary artery disease. A statistical analysis of intravascular ultrasound and coronary angiography in 1155 lesions. Circulation 1995; 91: 1959-65.

24. Prasad A, Herrmann J. Myocardial infarction due to percutaneous coronary intervention. N Engl J Med 2011; 364: 453-64.

25. Uetani T, Amano $\mathrm{T}$, Ando $\mathrm{H}$, et al. The correlation between lipid volume in the target lesion, measured by integrated backscatter intravascular ultrasound, and post-procedural myocardial infarction in patients with elective stent implantation. Eur Heart J 2008; 29: 1714-20.

26. Ekenbäck C, Jokhaji F, Östlund-Papadogeorgos N, et al. Changes in index of microcirculatory resistance during PCI in the left anterior descending coronary artery in relation to total length of implanted stents. J Interv Cardiol 2019; 2019: 1397895.

27. Niccoli G, Scalone G, Lerman A, Crea F. Coronary microvascular obstruction in acute myocardial infarction. Eur Heart J 2016; 37: 1024-33.

28. Zhang D, Xu B, Yin D, et al. Predictors and periprocedural myocardial injury rate of small side branches occlusion in coronary bifurcation intervention. Medicine 2015; 94: e992.

29. Bertinchant JP, Polge A, Ledermann B, et al. Relation of minor cardiac troponin I elevation to late cardiac events after uncomplicated elective successful percutaneous transluminal coronary angioplasty for angina pectoris. Am J Cardiol 1999; 84: 51-7.

30. Segev A, Goldman LE, Cantor WJ, et al. Elevated troponin-I after percutaneous coronary interventions: incidence and risk factors. Cardiovasc Radiat Med 2004; 5: 59-63.

31. Saito S, Shishido K, Moriyama N, et al. Modified jailed balloon technique for bifurcation lesions. Catheter Cardiovasc Interv 2018; 92: E218-26.

32. Numasawa Y, Sakakura K, Yamamoto K, et al. A novel side branch protection technique in coronary stent implantation: jailed Corsair technique. Cardiovasc Revasc Med 2017; 18: 2958.

33. Chen SL, Sheiban I, Xu B, et al. Impact of the complexity of 
bifurcation lesions treated with drug-eluting stents: the DEFINITION study (Definitions and impact of complEx biFurcation lesIons on clinical outcomes after percutaNeous coronary IntervenTIOn using drug-eluting steNts). JACC Cardiovasc Intv 2014; 7: 1266-76.

34. Sadamatsu K, Tashiro H, Yoshida K, et al. Acute effects of isosorbide dinitrate and nicorandil on the coronary slow flow phenomenon. Am J Cardiovasc Drugs 2010; 10: 203-8.

35. Su Q, Li L, Naing KA, Sun Y. Safety and effectiveness of nitroprusside in preventing no-reflow during percutaneous coronary intervention: a systematic review. Cell Biochem Biophys 2014; 68: 201-6.
36. Sakakura K, Funayama H, Taniguchi Y, et al. The incidence of slow flow after rotational atherectomy of calcified coronary arteries: A randomized study of low speed versus high speed. Catheter Cardiovasc Interv 2017; 89: 832-40.

37. Sakakura K, Inohara T, Kohsaka S, et al. Incidence and determinants of complications in rotational atherectomy: insights from the national clinical data (J-PCI Registry). Circ Cardiovasc Interv 2016; 9 .

38. Ndrepepa G, Colleran R, Braun S, et al. High-sensitivity troponin $\mathrm{T}$ and mortality after elective percutaneous coronary intervention. J Am Coll Cardiol 2016; 68: 2259-68. 